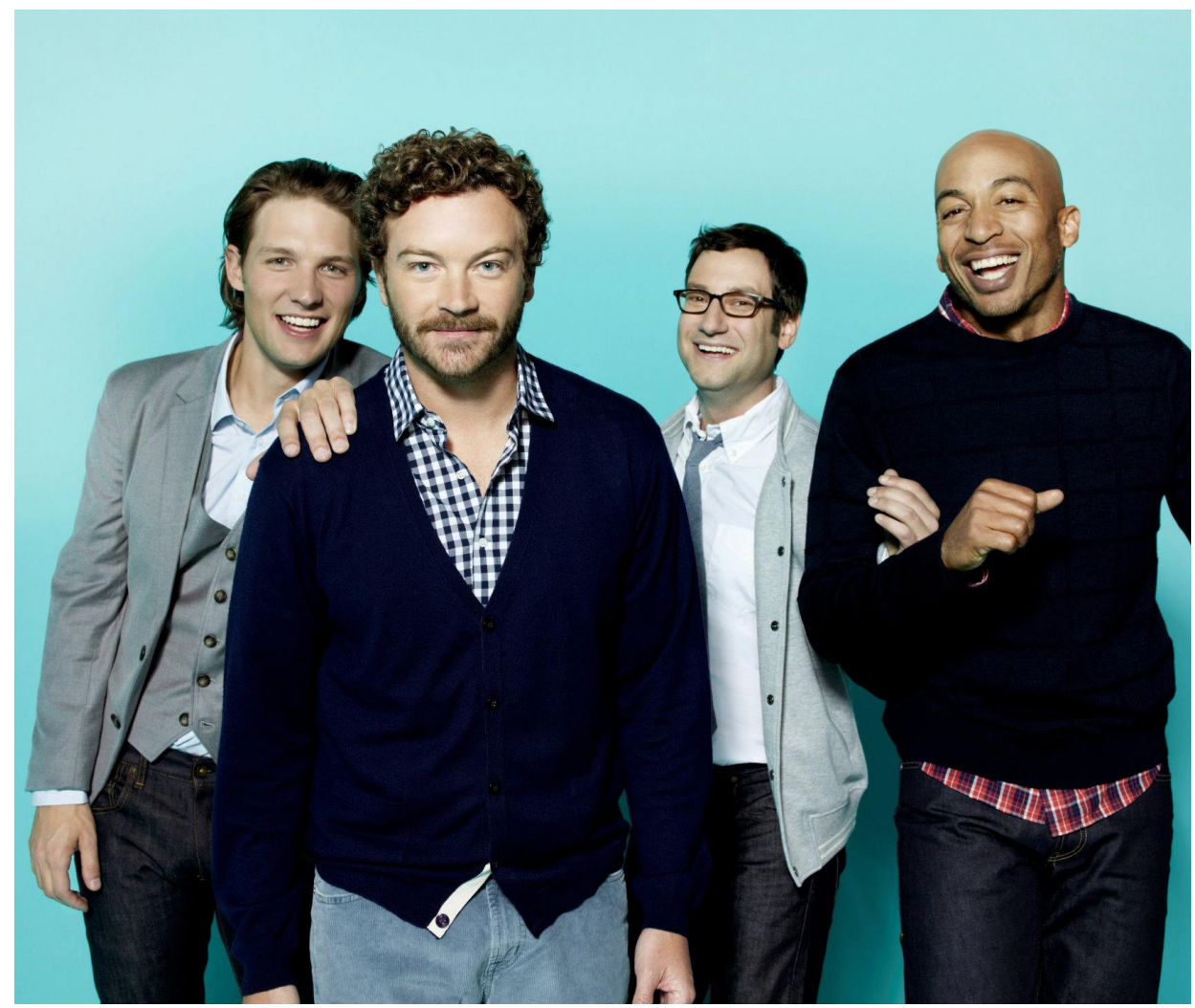

\title{
LA FICCIÓN EN LA TELEVISIÓN GENERALISTA NORTEAMERICANA Y LA REPRESENTACIÓN DE (NUEVAS) MASCULINIDADES
}

\author{
FICTION IN GENERALIST AMERICAN \\ TELEVISION AND REPRESENTATION \\ OF (NEW) MASCULINITIES
}

Francisco A. Zurian Hernández

UNIVERSIDAD COMPLUTENSE DE MADRID

Daniel Martínez Avila

UNIVERSIDADE ESTADUAL PAULISTA

Hernando C. Gómez Prada

INDEPENDENT SCHOLAR 


\section{RESUMEN}

En el texto se hace un recorrido por diferentes representaciones de personajes masculinos en la televisión generalista norteamericana que se escapan a la representación clásica de los personajes masculinos que tradicionalmente eran representados como personajes fuertes, valerosos y machos. Teniendo en cuenta cómo la ficción televisiva norteamericana cuenta con una máxima expansión -no solamente en Estados Unidos sino también, por su gran presencia en todas las televisiones occidentales, en Españapodríamos ver la repercusión que dichas representaciones pueden tener en los públicos en orden a construir nuevos imaginarios y nuevas referencias identitarias de lo masculino, la masculinidad y la virilidad.

PALABRAS CLAVE

Masculinidad, Hombre, Audiovisual, Género, Estética

\section{ABSTRACT}

The text offers a tour through different representations of male characters in American generalist television that are beyond the classical representation of the male characters that were depicted as traditionally strong characters, courageous and machos. Considering how American television fiction has a maximum expansion -not only in the US but, also for its strong presence in all Western television, in Spain- we could see the impact that these representations can make in the public in order to build new identitarian points of reference of the masculine, masculinity and virility.

KEY WORDS

Masculinity, Men, Audiovisual Gender, Aesthetics

Recibido: 23 de diciembre de 2014 Aceptado: 6 de febrero de 2015 


\section{INTRODUCCIÓN}

La ficción seriada televisiva desde mediados de los años noventa está siendo considerada, tanto desde la crítica audiovisual como desde el mundo académico y también las audiencias, como el paradigma de televisión de calidad, rompiendo así con un binomio que hasta hace poco se consideraba antagónico y que diferenciaba entre cultura popular y "alta cultura". Esta ficción, vinculada esencialmente a la producción de los canales de pago norteamericanos (aunque no de forma exclusiva), suele definirse desde parámetros como el riesgo narrativo, la creatividad, la originalidad e, incluso, la transgresión de tópicos tanto técnicos como argumentales. Sin embargo, algunos análisis que se han preocupado por incorporar enfoques epistemológicos no hegemónicos, como los efectuados desde los Gender Studies, los estudios sobre masculinidades y LGTBI o la teoría Queer, entre otras, encuentran que esa transgresión no siempre se produce en lo relativo a identidades genéricas pues la mayoría de ficciones consolidan lo que se ha dado en llamar heterosexualidad obligatoria además de feminidad/masculinidad normativas (Zurian, 2014, 9-10). Con todo, existen productos que han sido capaces de romper estas imposiciones patriarcales, conviviendo con aparente normalidad con los productos más mainstream e, incluso, producciones dirigidas y con la misma vocación que, no obstante, de alguna forma, tratan de ensanchar dichas tradicionales fronteras creativas abriéndose a representaciones más amplias.

El presente texto recorrerá algunas series norteamericanas paradigmáticas, mediante una metodología eminentemente teórica y estética con un marco de análisis flexible y relacional que, abierto a las contribuciones de nuevas disciplinas y epistemologías, puede contribuir al enriquecimiento de la investigación audiovisual. Se trata de ofrecer una lectura sobre la presencia y/o ausencia tanto del binarismo de género, la transgresión (si la hubiera) de los paradigmas identitarios genéricos así como las posibles propuestas emancipadoras de las representaciones dominantes (por la ideología patriarcal) de la masculinidad(es).
Los modelos de representación suelen usar estereotipos como repetidas constelaciones de rasgos negativos de los personajes que se convierten en una sólida forma de control social y que, además, implican a unos privilegiados de la representación, por eso, poner de manifiesto esas relaciones -de género pero también con implicaciones de raza, cultura y clase- lo que pretenden es conseguir una igualdad en la representación y un acceso a la propia representación.

\section{IDENTIDAD DE GÉNERO Y DISCURSO AUDIOVISUAL}

Es bien sabido que los medios de comunicación proponen formas de construir la identidad de género, así como modelos representacionales de dicha identidad (Zurian, 2011a, 7), de ahí que la forma de entender qué es masculino y femenino en esta sociedad eminentemente audiovisual responde a cierto modelo que se ofrece como canónico. La televisión no se escapa a esta tendencia sino que, de un modo todavía más incisivo crea dichos modelos canónicos, con tal fuerza, que llega, en algunos casos más sensibles -como entre los jóvenes y adolescentes- a convertirlos en prescriptivos (Zurian, 2013, 159-164) y uno de sus recursos es ofrecer situaciones y comportamientos a través de los que sugerir escenarios o protagonistas que la audiencia interiorice a través del proceso de inmersión e identificación espectatorial. La ficción es siempre una modelización del universo real, incluso en el caso de los productos más fantásticos. De ahí que la ficción televisiva ofrezca modelos del mundo que luego pueden ser reinterpretados y significados por la audiencia (Schaeffer, 1999, p. 218).

Existe consenso en la bibliografía especializada en cuanto a que las industrias culturales han reproducido el androcentrismo patriarcal, sin cuestionar los estereotipos de género y sin proponer lecturas alternativas que permitan observar los cambios que se están produciendo en la vida de hombres y mujeres. El análisis del protagonismo en la ficción revela un sesgo androcéntrico, al establecer de facto que el varón -y no cualquiera sino más bien el estereotípico- es el 
(único) sujeto significante. Tanto es así, que ni siquiera la audiencia se incomoda ante la hegemonía de lo masculino en menoscabo de lo femenino (o lo Queer). Esta circunstancia se traduce en la existencia de un mundo de ficción donde los varones poseen múltiples y ricas facetas y en el que se consolida un modelo de seducción apoyado en la iniciativa y autonomía masculina frente a unas mujeres dibujadas únicamente como cuerpo para ser mirado (y poseído). En este sentido, las mujeres siguen siendo el objeto, siempre en posiciones subordinadas o, en el caso de su protagonismo, dibujadas con elementos negativos la mayoría de las veces (Aguilar, 2001, p. 224). Todo ello contribuye al mantenimiento de cierta trivialización de lo femenino y, probablemente, a convertir en audiencias segmentadas los productos que están interpretados por mujeres. Estas características pueden explicar que el protagonismo femenino no sea una apuesta mayoritaria mientras que muchos productos televisivos se articulan en torno a argumentos familiares o profesionales.

Es por ello que en la raíz misma de la preocupación por las cuestiones de género es necesario (re)plantearnos tanto un repensar a la(s) mujer(es) como al(os) hombre(s) ya que si bien la dominación y la explotación (estructural, sistemática e histórica) ha sido sufrida por las mujeres por parte de los hombres, no es menos cierto que ellos han sufrido otro tipo de dominación patriarcal que les ha impuesto un concepto cerrado de sí mismos, de masculinidad única (unívoca y excluyente), así como de las relaciones entre los géneros, de la sexualidad y del sexo, encerrándoles en una heterosexualidad entendida como la única sexualidad posible puesto que lo "otro" quedaba, por lo tanto, en el lado de la enfermedad, la perversión, el "desvío" y el pecado nefando. Cuando se habla de representaciones y género se suele asociar inmediatamente la reflexión a la representación de las mujeres, a su posible cosificación, a la sexualización de su cuerpo, belleza o valores. Es mucho menos habitual hablar de la representación del(os) hombre(s) y, cuando se hace, se puede apreciar la su- ma incomodidad que provoca o, simplemente, se remite a una constatación de su rol dominante y protagonista (referida a la mujer) sin entrar en valoraciones sobre su corporalidad, la sexualización de su cuerpo y de su mirada, su belleza, su sexualidad y su deseo. La incomodidad del asunto conlleva el silencio. Y es que la cosmovisión del patriarcado ha sometido a los hombres a un rol de dominio con una interpretación de "lo masculino" normativa, única, exclusiva y excluyente de toda diferencia que provoca, por ello, una interpretación universalista de la "esencia" masculina que, a la vez, es propuesta como el universal y referencia absoluta del ser humano: la mujer viene de la costilla de Adán y, por lo tanto, el hombre es el referente total de la humanidad plena. Ese dominio se vuelve contra el propio ente dominante al no permitirle ser otra cosa que lo estipulado por la dictadura patriarcal, ningún hombre se puede definir por su propia especificidad particular sino, únicamente, por su ser universal "hombre". Pero, una vez puesto en cuestión el estatuto patriarcal no cabe más que poner en cuestión también su pretendida universalidad: ya no cabe hablar de "hombre" o "masculinidad" porque ya no es un concepto único, unívoco, normativo y exclusivo. De ahí que tengamos que hablar de "hombres" y "masculinidades" que no arrastran conceptos unívocos sino plurales, diversas sensibilidades y diferentes maneras de serlo. La ideología patriarcal se puede resistir al cambio, a la revolución (y sustitución) de paradigma pero ya es inevitable (Zurian, 2011b, 35-39).

\section{REPRESENTACIONES TELEVISIVAS DE (NUEVAS) MASCULINIDADES}

Los valores adjudicados a la masculinidad por el patriarcado (sexismo falocrático, heterocentrismo, individualismo, competitividad, activismo dominante, hegemonía, dominio de la esfera pública, minusvaloración de la esfera privada -propia de las mujeres-, permanente obsesión por el éxito, el trabajo, el ejercicio de la fuerza, la fortaleza y la represión de los niveles básicos emocionales y de las actitudes 
afectivo-relacionales) están en crisis. El macho se definía y representaba como el auténtico ser humano; él ostenta el poder y el dominio precisamente porque no es mujer, es decir, un ser débil, dubitativo, emocional, pasivo y dependiente, ni maricón, que no es sino la corrupción de la virilidad, un hombre que se corrompe al feminizarse y, por lo tanto, que ya no merece ser considerado masculino o una mujer que osaba salirse de su esfera para igualarse al hombre.

$\mathrm{El}$ macho es ajeno a "lo diferente", forma un todo común con los otros machos. Las diferencias raciales son percibidas como diferencias básicas en el desarrollo donde, por supuesto, el hombre occidental (blanco) representa el culmen de dicho desarrollo de masculinidad. Las diferencias de clase son percibidas por la ideología patriarcal también como manifestación de éxito pero no disminuían ni cambiaban el sentido de "macho" de esos hombres. Es por ello que "la masculinidad hegemónica se fundamenta y autoafirma a través del sexismo, el racismo y la homofobia” (Carabí, 1996, p. 28). Ante ese panorama lo que se plantea es un repensar en los valores plurales que puedan definir a los "nuevos" hombres. Se trata de una auténtica deconstrucción (de los viejos valores patriarcales) y una nueva reconstrucción de Adán (con los nuevos valores de la masculinidad liberada). Siguiendo el conocido argumento de Teresa de Lauretis (De Lauretis, 2000, p.36), el género es representación y la representación del género es su construcción. Es decir el género se construye en la representación de las ideas imperantes que señalan cómo debe actuar dicho género. De ahí la máxima importancia de intervenir en la representación, porque esa intervención libera el esquema normativo.

Y, en el sentido que nos ocupa, la cuestión es ¿cómo ha evolucionado la representación de las masculinidades en la televisión? ${ }^{1}$ Es una pregunta que, obviamente, excede las dimensiones de esta propuesta, aun acotando a la televisión norteamericana. Desde siempre han existido

1 Sobre ésta cuestión pero aplicada al cine, cfr. Zurian, 2015. personajes masculinos que, aún estando plenamente situados en el eje patriarcal introducían ciertos matices. La mayor parte de las veces por ser excesivamente "bonachones" y "tolerantes" con las "singularidades" de sus fuertes mujeres, aunque siempre terminaban por sobreponerse y situarlas en su sitio en la casa. Es el caso, por citar un ejemplo, de Darrin Sthephen en Bewitched (Sol Sacks, ABC, 1964-1972), lidiando con su duro trabajo de publicitario y con una mujer bruja (Samantha) a la que le prohíbe ejercer como tal pero que siempre se mete en algún embrollo muchas veces por la intervención de su madre Endora. Habitualmente este tipo de personaje encaja más en comedias ligeras familiares que en dramas o series policiacas donde la masculinidad se representaba siempre sin fisuras, como garantes, bien por policías, bien por jueces o abogados, del orden establecido.

La ficción televisiva, podríamos decir, se ha desarrollado según los cánones establecidos de la representación por el orden patriarcal aunque no ha sido ajena a los cambios sociales que se han ido produciendo. Así, por ejemplo, han irrumpido personajes protagonistas afroamericanos, el primero más célebre sin duda fue The Cosby Show (NBC, 1984-1992). Y, obviamente, poco a poco, han introducido personajes masculinos que se "desviaban" en ciertos "aspectos" tradicionalmente considerados masculinos, aunque siempre respetando la norma heterocentrista. La NBC ha sido una de las cadenas pioneras en la introducción de estos nuevos arquetipos de representación. Sitcoms como Fraiser; Friends (David Crane y Marta Kauffman, NBC, 1994-2004); Seinfeld (Larry David y Jerry Seinfeld, NBC, 19891998; años más tarde será también significativo el caso de la serie de uno de sus creadores, Larry David y su serie Curb Your Enthusiasm, HBO, 2000-actualidad); Mad about You (Paul Reiser y Danny Jacobson, NBC, 1992-1999) o Will \& Grace (David Kohan y Max Mutchnick, NBC, 19982005) replantearon incuestionablemente la masculinidad dominante y heteronormativa.

El caso de Fraiser (David Angell, Peter Casey y David Lee, NBC, 1993-2004; recordemos 
que se trata de un spin off de la serie Cheers, James Burrows, NBC, 1982-1993) es emblemático y muy avanzado. El hilo conductor de la serie es la representación de unas masculinidades diferentes, en clave de humor, pero que, episodio a episodio, cuestiona la norma masculina dominante. Frasier Crame es un psiquiatra que representa un hombre refinado, intelectual, de gustos exquisitos, un tanto snob, siempre bien vestido, con un apartamento de soltero de estudiado interiorismo -se enorgullece de su sofá copia del que tenía en su estudio Coco Chanel- ${ }^{2}$ y de modales tan delicados que le presentan como un heterosexual -sin dudas sobre su gusto por las mujeres- que parece siempre gay, un heterogay, tal vez el primero de la ficción televisiva, que solamente es ganado en refinamiento por su propio hermano Niles (David Hyde Pierce) y, por contraste, su padre (Martin, John Mahoney), un policía retirado que representa la clásica masculinidad que no sabe cómo encajar ni manejar a un(os) hijo(s) tan intensamente "sofisticado(s)". En la actualidad series como Entourage (Doug Ellin, HBO, 2004-2011) o Nip/Tuck (Ryan Murphy, FX, 2003-2010) juegan con el concepto de una masculinidad diversa, que muestra a unos hombres muchas veces perdidos en sí mismos, a quienes cuesta entender la evolución de la sociedad pero que desean ser triunfadores y vivir su propia vida, tomando sus propias decisiones sin seguir la estructura impuesta por el patriarcado, que pueden arrepentirse de lo acontecido en el pasado y cambiarlo.

Otra serie que indaga en la misma idea es la canadiense, también de audiencia en Estados Unidos, Josh y el sexo (Naked Josh, Alex Epstein y Laura Kosterski, Showcase, 2004-2006), donde se presentan dos modelos antagónicos de masculinidad: por un lado, el protagonista, Josh, un profesor de antropología sexual en la Universidad de Montreal, representante de ese nuevo hombre sensible que no busca relaciones

2 http://homonormativity2020.blogspot.com.es/2013/03/frasier-cranes-apartment-tvs-view-of.html (consultado el 10 de diciembre de 2014). esporádicas, sino un proyecto estable de pareja con una mujer y su propio proyecto de vida; por el otro, su amigo, el típico hombre mujeriego un tanto descerebrado pero que se da cuenta de que las mujeres son las que muchas veces le usan a él y no al revés, que tantas veces le gusta creer. La serie trata, en general, el complicado mundo de las relaciones personales y el sexo. No deja de ser significativo que una mujer sea co-creadora de la serie.

Big Shots (Jon Harmon Feldman, ABC, 20072008), por otra parte, es -pretendidamente- un Sex and the City (Darren Star, HBO, 1998-2004) pero a la masculina; a través de sus reuniones, los amigos podrán poner en común sus problemas con las mujeres o con su vida en general y tratar de darles una solución: nunca se vio en una ficción audiovisual, televisiva o no, hablar tanto a cuatro hombres. Con ella se trata de mostrar la pretendida problemática del hombre actual, que sigue un modelo de masculinidad que muchas veces le cuesta comprender la evolución de las relaciones de género y donde ellos no siempre detentan el poder, ni económico ni social ni sexual. O, más recientemente, Big Bang Theory (Chuck Lorre y Bill Prady, CBS, 2007-Actualidad), donde podemos ver diferentes formas de masculinidad también marcadas por cuestiones de cultura y raza. Los jóvenes físicos y profesores (del California Institute of Technology o "Caltech") protagonistas de la serie, son unos perfectos geeks, claro ejemplo del novedoso triunfo freak en la ficción audiovisual: patosos, fuera de la realidad, listos y de los cuatro protagonistas, uno es judío-americano y otro indio, enamorados de sus cómics, del cine de serie B, la ciencia ficción y en constante lucha por conseguir novia (salvo que Sheldon Cooper, Jim Parsons, que, simplemente, se la "encuentra" sin más).

También plantea cuestiones parecidas sobre la masculinidad la serie Chuck (Josh Schwartz y Chris Fedak, NBC, 2007-2012). Un joven enclenque e inteligente chico patoso (Chuck Bartowski, Zachary Levi) que por intervención informática se convierte en un superespía que, no 
obstante, necesita constantemente ser salvado por la atractiva, inteligente, fuerte, empoderada y determinada agente de la CIA, Sarah Walker (Yvonne Strahovski), de la que termina perdida y románticamente enamorado, en una clara transferencia de roles, según los esquemas clásicos de representación de género: él soñador, ensimismado, hablador, romántico y sentimental, y ella racional, fría, calculadora y distante.

Desde otra dimensión histórica Mad Men (Matthew Weiner, AMC, 2007-actualidad), ambientada en los años sesenta -al menos por ahora- sin embargo plantea (por contraste) las ideas mismas sobre masculinidad haciendo que, al visualizarla con los ojos de hoy, pensemos más si cabe en su transformación y cómo ha dejado de ser la norma hegemónica ese tipo de hombre macho hetero y prácticamente misógino. Otros destacados casos son Dexter (Showtime, 20062013); House (David Shore, Fox, 2004-2012) o Scrubs (Bill Lawrence, NBC, 2001-2008 y ABC, 2008-2010).

Quisiéramos destacar el fenómeno televisivo que está siendo la serie de Alan Ball, ${ }^{3}$ True Blood (HBO, 2008-2014), un ejemplo de cómo desde una realidad fantástica situada en un futuro cercano en el que los vampiros y otros seres -mutantes, hombres lobo, brujas y brujos, hadas y hados, etc.- conviven (más o menos bien) con los humanos. Gracias a esa gran variedad de seres se nos proponen también un sin fin de cuestiones sobre género y, concretamente, sobre los valores y articulaciones de sus respectivas masculinidades nunca definidas por su orientación sexual -una gran novedad a la hora de definirla- y que incorporan, además, una estética erótica permanente y buscada. La presencia de la sexualidad es continua y tanto mujeres como hombres constantemente muestran sus deseos, sus cuerpos, su actividad sexual y sus inclinaciones. Con

3 Creador de una serie emblemática que suele ser citada como el inicio de una nueva televisión, Seis metros bajo tierra (Six Feet Under, HBO, 2001-2005) importante también para el estudio de las representaciones de las masculinidades, con un abanico variado de hombres, con diferentes orientaciones sexuales y diferentes modos de encarnar su propia masculinidad. total naturalidad se muestran personajes heterosexuales, homosexuales y bisexuales, hombres y mujeres, que muestran cómo dicha orientación sexual no supone ningún tipo de menoscabo a su identidad como hombre o como mujer. Resulta significativa y novedosa esta forma de representar las masculinidades que no son un cuestionamiento a la masculinidad per se, sino un cuestionamiento a la ideología patriarcal sobre la masculinidad y sus (apriorísticas) imposiciones ideológicas. No se pretende cuestionar ni la propia masculinidad ni la de los demás. Aquí permanentemente se ven los cuerpos desnudos de vampiros, vampiresas, hombres y mujeres lobo, mutantes, brujas y brujos, hadas y hados y, por supuesto, también los humanos; se les ve tener sexo con mujeres o con hombres (o con ambos) y se consigue que el espectador masculino siga la serie sin entrar (al menos del todo) en esa incomodidad defensiva que tantas veces le puede producir la visualización de la desnudez corporal de otros hombres por sentir vulnerable, de ese modo, su masculinidad. El éxito puede deberse a ese ambiente "mágico" que plantea una neo-realidad pero también es cierto que se consigue una normalización en el visionado haciendo girar el objeto del (placer) visionado (Mulvey, 1988).

Men at Work (Breckin Meyer, TBS, 2012-2014) es, seguramente uno de los más preclaros ejemplos actuales. Una sitcom que se nos presenta con unos títulos de créditos con fotografías, de principios del siglo XX, de hombres trabajando (mayoritariamente) en trabajos físicos, hombres prematuramente mayores, serios, abrumados, duros, sudorosos, sucios, velludos, descuidados y de contundente presencia física no estetizada, que contrasta con los cuatro protagonistas: hombres heteros de físicos cuidados, fibrados pero no musculados, se nota que la mayoría de ellos hacen habitualmente ejercicio físico -tal vez menos Adam Busch, interpretado por Neal Bradford que, curiosamente es el único con novia en la serie- pero como placer y/o opción saludable y estética, no por obligación -como los hombres de los títulos de crédito- y con profesiones na- 
da "físicas": editores, escritores y fotógrafo de una (norteamericana) revista masculina. Milo (Danny Masterson) es abandonado por su novia y nos ofrece un cambio de roles en la habitual representación de este tipo de secuencia: él intentando (suplicándole) que ella no le deje, ella diciéndole que no es por él sino por ella... Sus tres amigos y compañeros de trabajo le ayudarán a "volver al mercado" de solteros al que pertenecen dos de ellos -el blanco rubio y guapo, Tyler (Michael Cassidy), y el afroamericano ligón, Gibbs (James Lesure)- puesto que el único que tiene pareja es, en definitiva, el hombre que, a priori, según el esquema tradicional, es el menos masculino, el menos guapo, el menos cool, el más débil, el más raro... Por ejemplo, en el capítulo 4, "Heterotextual" -en la versión doblada al español lo definen como "Machotextual"-, sus amigos le explican a Milo cómo ser un hombre interesante para las mujeres del 2012 después de los años que ha estado con novia y, por ello, desconectado de la nueva realidad de las mujeres.

Todos estos ejemplos nos hacen ver cómo las ficciones televisivas siguen siendo uno de los pilares básicos de la construcción del imaginario social y, por eso mismo, una de las principales herramientas en el cambio de mentalidad que se está operando en la construcción de las nuevas masculinidades. No en vano es un trabajo arduo que necesita referentes ya que consiste en desmontar toda la mitificación de la masculinidad y la heterosexualidad normativa operada por el patriarcado y acomodarla a una realidad donde la mujer es un sujeto activo tanto a nivel personal, social, profesional, económico, político y sexual.

En general podemos ofrecer una catalogación de características a la hora de la construcción de los personajes masculinos y de su arco de personaje, con la premisa mayor (siempre) de no ser personajes que ofrezcan una masculinidad universal ni un modelo de representación como metáfora de un hombre que engloba todo el sentido de la masculinidad e, incluso, de la humanidad misma. Toda construcción de personajes juega con la simplificación de la realidad en la generalización de una imagen consensuada por un grupo de personas o grupos, sobre otras personas u otros grupos, que se transfieren en el tiempo. Con todo, en la construcción de relatos, en la creación de ficción y, en general, en el artificio de la representación, el uso de los arquetipos es ocurrente y necesario en orden, por un lado, a la construcción de caracteres (personajes) y, por otro, a facilitar la identificación por parte del público (consumidores). De este modo los arquetipos juegan con modelos de caracterización que permiten esa doble necesidad por medio de la descripción física, psicológica y del entorno social. En el caso de los personajes masculinos se suele desarrollar, en cuanto al físico, una obsesión por la fuerza, la dureza y los músculos, incluso por la búsqueda de una belleza masculina, especialmente en la actualidad. El cuerpo como muestra de vigor y virilidad. La corporalidad como manifestación de su poder y su capacidad de triunfo. Ahora también como arma de seducción -anteriormente solamente se contemplaba ésta posibilidad en las mujeres- y poder sexual: se fomenta la mirada de la mujer hacia la corporalidad masculina pero también la mirada homoerótica y no solamente buscando la complicidad con el posible público gay. Pero ahora, a diferencia de otros tiempos, el cuerpo ya no tiene que ser necesariamente velludo, se visibiliza también el cuidado corporal por medio de cuerpos depilados -o con el vello "justo", delineado y nunca donde no debe estar-, forjados en el gimnasio y nada ajenos ni a la moda ni a su conciencia de poder sexual. Si antes el modelo era un Tarzán salvaje ahora es un hombre mucho más sofisticado, aunque duro, cuidado y moldeado, buscando definición cuando no un gran volumen de músculos, marcando un pecho grande y fuerte, visibilizando los abdominales de forma escultórica y piernas recias, dejando insinuar un buen tamaño en su miembro viril.

En cuanto a su psicología, tradicionalmente los hombres se solían mostrar racionales y poco sentimentales, individualistas -aún estando en grupo- y ambiciosos (acompañado todo ello de una cierta arrogancia y suficiencia), muy 
competitivos, sin miedo, con arrojo y valentía (muchas veces temerarios), eran líderes natos, agresivos para defender su territorio y su posición de dominio; si le es útil mentirá y manipulará, es peligroso y no tolerará la infidelidad ni la traición; pero actualmente se han vuelto mucho más complejos. Se reconocen más vulnerables, menos seguros de sí mismos o, mejor, con una seguridad menos soberbia pero con "actitud", más comprometidos, su trato con las mujeres y su nivel de compromiso de pareja son más respetuosos y más igualitarios. En cuanto a su entorno social tradicionalmente el hombre ocupa por definición la esfera de lo público -el trabajo, política, deporte, diversión, bares- y el poder; se remarca su profesionalidad y su sociabilidad; es el cabeza de la familia (ahora menos); se siente (y es) libre, autónomo, con capacidad de decisión y de elección, participa en equipo (en el deporte, en la ganadería amistosa, los negocios, etc.). Actualmente se le presenta también en la esfera privada, tradicionalmente lugar de los personajes femeninos: el hogar, la familia y la intimidad con su pareja y/o amigos ya son un lugar común para los personajes masculinos. También lo podemos ver vulnerable, dependiente -incluso de una mujer- y desorientado. El hombre puede abarcar ya cualquier ámbito de representación social. Y esa es una muestra de la transformación de su arco de personaje y una muestra preclara del cambio acaecido.

Usualmente se establecían ciertos modelos de caracterización típicos como eran el macho, el donjuan, el guerrero, el héroe, el indomable, el villano, el padre (Zurian, 2011c, 290). Los estereotipos de los hombres en la ficción audiovisual tienden a ser atractivos, con personalidad y activos, mientras que las mujeres quedan relegadas al grado de jarrón, detrás, sin apenas ningún tipo de actividad interesante que se aleje de la mera contemplación de su belleza o de su bondad y virtudes como mujer según la visión del patriarcado. Actualmente podemos hablar también del inadaptado, el antihéroe, el eterno adolescente inmaduro (síndrome de Peter Pan), el profesional, el padre, el hijo, el amigo. Se pueden esta- blecer dicotomías que vienen marcadas por la diferente caracterización de los personajes masculinos; así podemos tener, hombres de apariencia vulgar frente a hombres guapos; perdedores, frikis, geeks, nerds, frente a triunfadores, dominantes, machos alfa; inmaduros, eternos adolescentes o postadolescentes, frente a hombres maduros, con objetivos y un proyecto vital; hombres normales (ordinarios) frente a héroes y, por supuesto, hombres heterosexuales frente -pero no necesariamente enfrentados, como sucedía antes- a hombres homosexuales. Aunque lo que más destaca en este cambio de las políticas de representación no es tanto el rol sino, más bien, la forma nueva de encarnar dichos roles. Por eso se trata, como decíamos, de "des-universalizar" lo masculino (patriarcal) de la misma manera que otros factores que determinan la identidad están particularizados. Basta con contemplar a cada hombre en su singularidad, como encarnación diferente y plural de los diferentes modelos masculinos propios de las culturas y sociedades donde se ubican, abandonando para siempre el vocabulario y la representación que ponga en el mismo plano lo masculino y lo humano.

\section{CONSIDERACIONES FINALES}

La ficción televisiva contemporánea, si bien no ha roto con los estereotipos de género ni se ha convertido en un vehículo de emancipación femenina o cuestionamiento de la masculinidad canónica patriarcal, sí estaría permitiendo la irrupción de nuevos discursos ficcionales que comienzan a socavar las bases androcéntricas y heteronormativas de los discursos mediáticos. Las negativas críticas que, en ocasiones, reciben las series protagonizadas por mujeres o por personajes masculinos que no responden al arquetipo viril dominante quizá explican la incomodidad que todavía siente la sociedad ante quienes deciden no plegarse a los designios normativos patriarcales. La desvalorización de "lo otro" puede observarse en que, generalmente, las series que hemos recogido en los epígrafes precedentes, muchas de ellas con gran calidad técnica y creativa, riesgo narrativo y apuestas novedosas en lo estético y discursivo, no 
suelen incluirse en los listados sobre las mejores series de televisión, tan de moda entre crítica e investigadores/as. Sin embargo, y aunque no disfruten del estatus que muchas de ellas merecen, desde un punto de vista de género ofrecen retos imprescindibles para la reflexión contemporánea puesto que permiten proponer otros modos de representar el género y la sexualidad, amplían el espectro representacional y ofrecen distintos (y variados) modelos de representación que, sin duda influyen en el público y en la visión social general. El audiovisual como vínculo de expresión de la realidad social y de los cambios que se operan en su seno, así como motor de dicho cambio tiene en los productos ficcionales televisivos una de sus principales herramientas y armas de transformación.

\section{REFERENCIAS BIBLIOGRÁFICAS}

Aguilar, P. (2001). Mujeres de cine: retratos mágicos pero distorsionados. En B. Muñoz (coord.), Medios de comunicación, mujeres y cambio cultural (pp. 221-244). Madrid: Dirección General de la Mujer de la Comunidad de Madrid.

Carabí, À. (2006). Construyendo nuevas masculinidades: la representación de la masculinidad en la literatura y el cine de los Estados Unidos (1980-2003). Madrid: Instituto de la Mujer.

De Lauretis, T. (2000). Diferencias. Madrid: Horas y Horas, p.36

Mulvey, L. (1988). Placer Visual y cine narrativo. En Eutopías, 2a época (Documentos de trabajo del Centro de Semiótica y Teoría del Espectáculo, Departamento de Teoría de los Lenguajes, Universidad de Valencia). Valencia: Ediciones Episteme.

Schaeffer, J. M. (1999). Pourquoi la fiction? París: Seuil.

ZURIAN, Francisco A. (2011a). "Sexualidad y políticas de género en el audiovisual" en Zurian, Francisco A. (Coord.): Secuencias. Revista de Historia del Cine, monográfico, 34, pp. 7-10.

ZURIAN, Francisco A. (2011b). "Héroes, machos o, simplemente, hombres: una mirada a la representación audiovisual de las (nuevas) masculinidades" en Zurian, Francisco A. (Coord.): Secuencias. Revista de Historia del Cine, monográfico, 34, pp. 32-53.

ZURIAN, Francisco A. (2011c). "Almodóvar, la identidad de género buscada: el caso de La piel que habito" en Zurian, Francisco A. (Ed.) Imágenes del Eros. Género, sexualidad, estética y cultura audiovisual, Madrid: Ocho y medio libros de cine, pp. 277-297.

ZURIAN, Francisco A. (2013): "Cuerpos masculinos, hormonas y sexo en la ficción televisiva" en Zurian, Francisco A. (Ed.) Imagen, cuerpo y sexualidad. Representaciones del cuerpo en la cultura audiovisual contemporánea. Madrid: Ocho y medio libros de cine, pp. 157-175.

ZURIAN, Francisco A. (2014): "Los estudios de género y la teoría fílmica feminista como marco teórico y metodológico para la investigación en cultura audiovisual" en Zurian, Francisco A. (Coord.) Área Abierta, vol. 14, n० 3, monográfico "Feminismo, estudios sobre mujeres y cultura audiovisual, noviembre, pp. 5-21.

ZURIAN, Francisco A. (2015, en prensa): "Construyendo la representación audiovisual de (nuevas) masculinidades en el audiovisual mainstream norteamericano" en Zurian, Francisco A. (Ed.) Diseccionando a Adán. Representaciones audiovisuales de la masculinidad. Madrid: Síntesis. 